Voix et Images

voixetimages

\title{
Inédit. Extrait de Yvel Swanson
}

\section{Yolande Villemaire}

Volume 11, numéro 3 (33), printemps 1986

Yolande Villemaire

URI : https://id.erudit.org/iderudit/200574ar

DOI : https://doi.org/10.7202/200574ar

Aller au sommaire du numéro

\section{Éditeur(s)}

Université du Québec à Montréal

\section{ISSN}

0318-9201 (imprimé)

1705-933X (numérique)

Découvrir la revue

\section{Citer ce document}

Villemaire, Y. (1986). Inédit. Extrait de Yvel Swanson. Voix et Images, 11(3),

384-387. https://doi.org/10.7202/200574ar d'utilisation que vous pouvez consulter en ligne.

https://apropos.erudit.org/fr/usagers/politique-dutilisation/ 


\title{
INÉDIT
}

\section{Extrait de Yvel Swanson}

\author{
Yolande Villemaire
}

New York rutile dans ma mémoire, éclats d'or dans les vitres, glacis des façades, vapeurs qui s'échappent de l'asphalte et nous enveloppent de nuages mouvants dans l'air froid de cet hiver où nous nous sommes rencontrés. Je marche sur Avenue of the Americas, les yeux fixés sur les tours jumelles du World Trade Center qui scintillent dans le crépuscule. Je ne sais pas encore que notre destin est scellé dans les étoiles et que tu viens vers moi, traversant les mers et les continents, aussi sûrement que je vais vers toi ravie par la petite neige qui tombe doucement sur Manhattan, l'odeur des sapins qu'on vend au coin des rues et les grelots de l'Armée du Salut.

Je sens, ce jour-là, que la vie me réserve le privilège incomparable de l'amour, du grand amour, de l'éternel amour pour lequel je suis née. Les dix dernières années de ma vie m'auront brisée pour que j'arrive, muée, à cette fin de siècle bouleversante dont la vague extatique nous dépose au seuil de l'an 2000.

Cette planète est ma terre natale et je I'aime inconditionnellement, comme on aime sa propre mère. Je sais qu'elle tourne dans un vaste univers que j'aime, inconditionnellement, comme on aime son propre père. Des étoiles m'est parvenu, il y a dix ans, comme à beaucoup d'autres, à vous aussi peut-être, un message. Un signal sonore, si on veut, qui a déclenché une mutation de tout mon être. J'étais debout sur une plage, la nuit, quelque part sur cette terre quand la transmission s'est produite. J'étais avec un ami. Nous savons, maintenant, oui, que cela s'est produit. Mais en juillet 1975, nous en étions parfaitement inconscients.

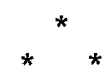

\section{L'histoire de Vava}

Mon nom est Vava Lafleur. Je suis née, quatre ans après la dernière grande guerre, dans un petit village non loin de Montréal qui est maintenant devenu l'aéroport international de Mirabel. C'est un certain docteur Labonté qui m'a mise au monde, dans la petite maison de la Montée des Anges construite par mon père. 
J'ai tout de suite aimé ma grand-mère qui pleurait de joie et murmurait: Que c'est beau la vie en se tordant les mains tandis que je hurlais de rage à cause des forceps. Elle est morte il y a plus d'un an maintenant mais je sens encore sa présence bienveillante autour de moi dans mon studio ensoleillé au quatorzième étage d'un immeuble de Manhattan.

C'est la tête en bas que j'ai décidé d'en vouloir pour l'éternité au sale type qui me tenait par les pieds. Le pauvre docteur Labonté, que Dieu ait son âme, n'avait jamais vu un nouveau-né aussi furieux. Ma colère venait de loin, de très loin, d'aussi loin que la nuit des temps.

J'ai eu la chance extraordinaire d'avoir une mère joueuse et confiante, ravie d'avoir un bébé à qui elle pourrait apprendre tout ce qu'elle avait appris. Je me rappelle notre premier mois de mai ensemble, le crissement des roues du pousse-pousse sur la petite route qui mène au village, la chaleur du soleil sur mon visage, la petite oie de caoutchouc que papa m'a donnée et que je tiens précieusement contre mon coeur. Maman s'arrête tout à coup, se penche vers moi pour me faire sentir le bouquet de lilas qu'elle a coupé pour sa mère à elle chez qui nous allons passer l'après-midi. Je revois les minuscules fleurs qui dansent dans mon visage, me chatouillent les joues, les yeux clairs de maman, sa belle bouche rouge, l'odeur miraculeuse du lilas. Elle me dit, en souriant, que je vais avoir une belle vie, une très belle vie et m'embrasse dans le cou. Je roucoule.

Grand-maman avait les cheveux blancs même quand j'étais toute petite. Quand il m'arrivait de dormir chez-elle, j'étais toujours émerveillée de la voir dérouler sa toque et déployer ses longs cheveux soyeux qu'elle peignait longuement avant de se mettre au lit. Je.me blotissais contre son épaule, le nez dans ses cheveux, le cour battant au rythme de l'horloge qui mesurait l'éternité de mon bonheur.

Grand-maman aussi avait une mère. On l'appelait memère. Elle était vieille et vivait chez matantè Ida, à l'autre bout du village. Memère était en chaise roulante et elle était toujours contente de me voir arriver dans mon pousse-pousse. Mais quand j'ai commencé à marcher, elle avait peur que je brise ses beaux bibelots. Elle est morte quand j'avais quatre ans, un an avant qu'on déménage en ville.

Popa avait acheté un terrain dans Ahuntsic, dans le nord de la ville, et avait construit une maison dans laquelle nous sommes déménagés un jour de grand soleil, incomparablement excités à la perspective d'une nouvelle vie. J'ai grandi dans l'odeur du bois et du mastic, la musique des scies rondes et le vacarme des camions de ciment en train de couler les fondations d'une nouvelle maison. Ahuntsic était alors un chantier de construction, un quartier où on avait pas encore asphalté les rues et construit les trottoirs, un immense terrain vague semé des petites cabanes d'immigrants qui s'y étaient installés et y 
cultivaient des jardins potagers et des fleurs. La nuit, les boules noires aux abords des sites d'excavation, crachaient un feu qui ne brûlait pas.

Ninine et moi on avait beaucoup de poupées et un chat qu'on habillait avec le linge des poupées et qu'on promenait dans le carosse du bébé. Coco commençait à peine à marcher mais on l'amenait prendre des marches des fois avec les poupées et le chat. On avait pas le droit de sortir de la cour ni de jouer avec les autres enfants. De toute façon, ils ne parlaient pas le français.

Un jour, moman m'a emmenée voir l'école où j'irais. J'étais contente d'aller à l'école à cinq rues de chez-nous. Popa, quand il était petit, devait marcher un mille pour aller à l'école. Et, en plus, dans ce temps-là, des fois, lui et ses petits frères n'avaient pas de souliers. Ils étaient dix-sept enfants dans la famille de popa mais plusieurs étaient morts. J'avais seulement sept mononcles et quatre matantes du côté de popa, il y en avait cinq qui étaient morts en bas âge. J'avais six mononcles et deux matantes du côté de moman. Grand-maman Larose avait perdu son mari à l'âge de trente-six ans, c'est pour ça qu'elle avait eu moins d'enfants que grand-moman Lafleur. Elle avait aussi perdu un fils, mononcle Eugène, que je n'ai jamais connu et qui est mort à dix-neuf ans, de la fièvre typhoïde quand il travaillait sur les trains du Canadien Pacifique.

Nous on était trois jusqu'au jour où moman nous a assis sur son lit, Ninine, Coco et moi, pour nous annoncer qu'on aurait un autre petit frère ou une autre petite sœur. On était contents. Quand le bébé est arrivé de l'hôpital avec moman, on l'a pris dans nos bras et on a regardé ses beaux petits doigts. Ça m'a fait chaud au cœur quand j'ai senti sa toute petite main se fermer sur mes doigts. Il sentait bon et il pleurait très fort parce qu'il avait des coliques. Quand je n'avais pas d'école, je le berçais en regardant des films à la télévision. Je faisais semblant que c'était mon bébé à moi comme dans le film où le petit garçon et la petite fille se retrouvent seuls sur une île après un naufrage, se bâtissent une maison et se retrouvent, je ne comprenais pas comment au juste, avec un bébé.

On avait été les derniers à avoir la télévision. Avant, j'allais regarder les petits bonhommes chez mon ami Gilles avec qui j'allais à l'école et qui restait en bas de chez-nous. Quand on a eu la télévision, je regardais les petits bonhommes chez-nous avec Ninine et Coco sauf quand ils ont eu la rougeole parce qu'ils n'avaient pas le droit de sortir de leur chambre.

Le film que j'aimais le plus c'était le Voleur de Bagdad. Ça passait presque toujours le jour de Noël, quand il y avait de la visite, ça fait que j'en manquais des bouts. Ce que j'aimais le plus, c'est quand le petit voleur de Bagdad regarde dans l'oeil de l'idole des Indes qu'il a volé et que tout le paysage se transforme. Il aperçoit une grande tente 
blanche dressée dans le désert. Il entre. Des vieillards à longue barbe blanche lui disent alors ce qui me donnait des frissons à chaque fois : Voilà deux mille ans que nous t'attendions, Sabu. Je rêvais qu'un jour cela m'arrivait à moi, de dérober une pierre précieuse et de me retrouver magiquement devant une immense tente dans laquelle j'entrais et où de nobles vieillards me disaient: Voilà deux mille ans que nous t'attendions, Vava.

Mais j'allais à l'école des Saints-Martyrs-Canadiens, c'était loin des Mille et Une Nuits. J'aimais l'école mais c'était ennuyant. Je passais beaucoup de temps à regarder la grande aiguille de l'horloge au-dessus de la porte s'approcher du chiffre douze. À quatre heures précises, la cloche sonnait, nous délivrant d'une autre longue journée passée à apprendre que le complément d'objet direct du verbe avoir placé avant s'accorde et que neuf fois neuf fait quatre-vingt-un.

New York, février 86 